\title{
Repercussions of Emotional Intelligence on Leaders Behaviour
}

\author{
${ }^{*}$ Mr. Hardik Nayee
}

Assistant Professor, Kalol Institute of management (Affilated to Gujarat Technological University, Ahmedabad), KIRC Campus, Kalol - 382721 Gujarat (India)

\begin{abstract}
There are many factors that influence the behaviour of Human Being and so as the behaviour of a Leader. The repercussions of emotional intelligence on the behaviour of the Leader are to be studied. The term Emotional intelligence (EI) is considered as an ability or capacity or skill or self-perceived ability to identify, assess and manage the emotions of oneself, of others, and of groups. It becomes one of the key indicators of employee's success at workplace. EI matters most than the Intelligent Quotient (IQ) under the premise that some people are academically good but still fail in their social and interpersonal associations. With the right emotional intelligence skills, one can have control over these emotions and be successful at workplaces. Life at workplace can be so much more enjoyable sans this emotional spitefulness. EI helps people to get to more personal and professional relationships and progress further at workplace. It is the ability to identify oneself and analyze and solve problems that enables one's own development.
\end{abstract}

Keywords: Emotional intelligence, Leader, Behaviour, Human Being

\section{Article Publication}

Published Online: 31-Jul-2021

\section{*Author's Correspondence}

8 Mr. Hardik Nayee

8 Assistant Professor, Kalol Institute of management (Affilated to Gujarat Technological University, Ahmedabad), KIRC Campus, Kalol - 382721 Gujarat (India)

$\bowtie$ hardiknayee1993@gmail.com

C 2021The Authors. Published by

International Journal of Management and Development Studies

This is an open access article under the

CC BY-NC-ND license

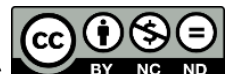

(https://creativecommons.org/licenses/b y-nc-nd/4.0/)

\section{Introduction}

Emotional intelligence is constituted by two components one is Emotion and other is intelligence. Emotions are internal events that many psychological subsystems including psychological responses, cognitions, and conscious awareness. Emotions typically arise in responses to a person's changing relations. Intelligence means the capacity and ability to solve the problems. In organization both constituents are working towards common goals. Emotional intelligence and its implication for leaders should primarily focus toward organizational intelligence. An effective leader always uses the EI as a trigger for managing OI. Organizational Intelligence as the capability and competency of an organization to comprehend and concluded knowledge relevant to organization purpose. Organizational intelligence focus includes the creation, development and retention of organizational competencies. An organizational works by the people, of the people and for the people. In simple words it is people management. So a leader displays lots of pieces of intelligence in terms of individual competencies. 


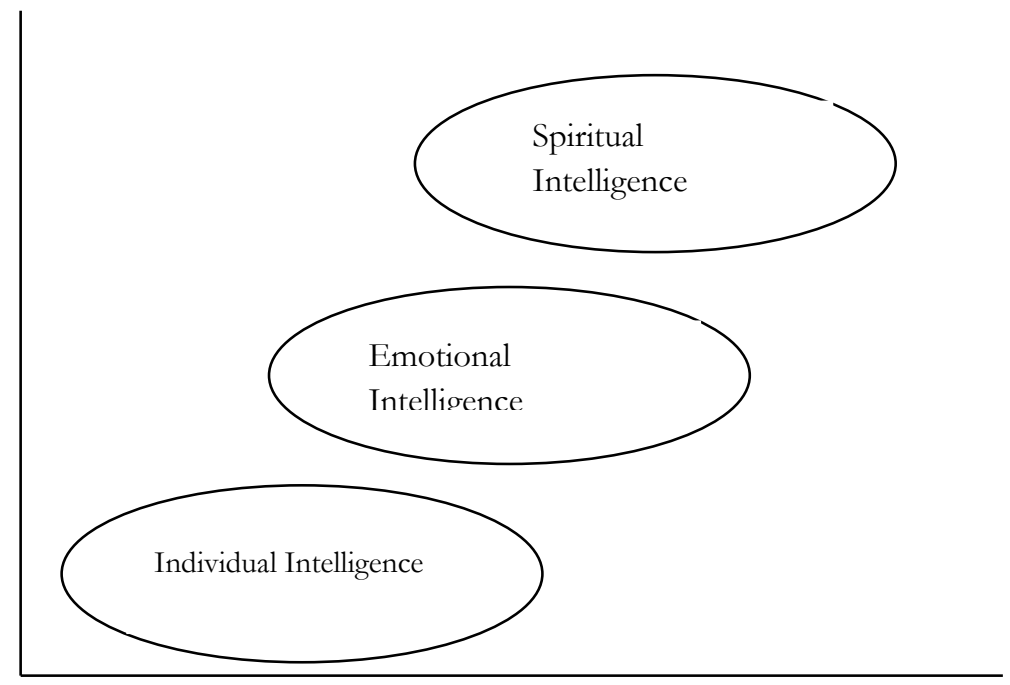

Figure1: Organizational Intelligence Quotient Hierarchy

Individual intelligence is measured by intelligence Quotient (IQ), which broadly reflects and individual capability and competency to understand and evaluate a problem. But by far what is more important for a leader is- synchronization of these intelligence pieces into an intelligent so as to create ORGANISATIONAL INTELLIGENCE, smartly.

Emotional intelligence is the ability to accurately perceive the emotions in one self and others, understanding emotional meaning and managing emotions. EI is measured as Emotional quotient (EQ). It reflects an extension of self- understanding introspection and observation.

Spiritual intelligence motivates people to balance their work and family. This intelligence creates an ability to complete oneself by fulfillment of needs. It is measured as Spiritual Quotient (SQ). Organizational intelligence quotient which is measured as a function of individuals IQs added to EQs and SQs. Hence the Organisational Intelligence can be equated as under:

$\mathrm{O} . \mathrm{IQ}=\mathrm{IQ}+\mathrm{EQ}+\mathrm{SQ}$

O.IQ is organizational intelligence Quotient which is summation of all the quotients which exists in its human capital and to use them intelligently so as to respond smartly and sharply to ever changing environment.

IQ preliminary is the ability to solve logical problems.

EQ allows us to judge the situation we are in and behave appropriately

SQ allows us to ask if we want to be in that situation, we are in that situation in the first place and then finding the alternate.

\section{Emotional intelligence to the workplace for organizational success}

All the Leaders are continually encountering emotions either of own or that from others. These emotions are positive as well as negative. Leader's ability to overcome and get out of the effect of a particular emotion is known as emotional Intelligence. If a leader, least affected by such emotions is supposed to be having high emotional intelligence. If overwhelmed by emotions is one with low emotional intelligence.

In the words of Goleman, People who rise to the top, of their field aren't just good at their jobs; they're affable, resilient, confident, optimistic, etc. In this sense EQ is explained as the ability to restrain negative 
feelings, such as anger and self-doubt, and focus on positive ones, like confidence and congeniality. To Goleman, Cognitive Skills [IQ] may get you in the door of a company, but [EQ] helps you thrive once you you're in. For example, success in sales requires the empathic ability to gauge a customer customer's mood and those interpersonal skills to decide when and how to pitcha product and when to keep quiet.

Dave McClelland (1998) a Harvard psychologist, reviewed data from more than 30 diverse organizations and professions, from banking and management to Sales and Health from Health-Care. He concluded:

- A wide range of emotional intelligence competencies Emotional Competencies Consistently distinguished top performers from average Ones

- The EQ Competencies that Distinguished Most Powerfully:

$\checkmark$ Achievement Drive [Optimism, Striving to Improve Performance];

$\checkmark$ The Ability to Develop Others [Sense Needs/Bolster]

$\checkmark$ Adaptability [Managing Change/Open to New Ideas]

$\checkmark$ Influence [Sense Emotions in Others/Persuasion]

$\checkmark$ Self-Confidence [Self Aware Strengths/Weaknesses]

$\checkmark$ Leadership [nspire Others to Shared Vision]

- The different clusters of competencies:

EQ is the ability to recognize and understand "Emotions" [leaders and those of the people interact with] and the skill to use that awareness to effectively manage leaders and relationships with others! EQ is a major indicator of achievement. It explains why individuals with similar intelligence can reach vastly different levels of success in their professional and personal lives. While strong Intellect [IQ] and experience may get individuals into professional positions - EQ spells the difference between those who excel and those who Under-Achieve!

\section{Emotional Intelligence [EQ] Consists of Four Learned Competencies:}
1. Self-Awareness
2. Social Awareness
3. Self-management
4. Relationship management

\section{Self-Awareness-}

Self-awareness the ability to perceive and understand our own emotions and the behavior that flows predictably there from;

\section{Social Awareness -}

The ability to read and understand the emotional cues and responses/reactions of other people;

\section{Self-Management-}

The ability to apply this new awareness to more effectively direct \& manage ourselves; and

\section{Relationship Management-}

The ability to build more effective and productive relationships with others and to build on our own achievement \& success

\begin{tabular}{|l|l|l|}
\hline & What leader observe & What leader do \\
\hline Personal competence & Self-Awareness & Self-Management \\
\hline Social Competence & Social Awareness & Relationship Management \\
\hline
\end{tabular}


Table: The Matrix showing the Emotional Intelligence chart for leaders (source:(Bradberry, Quickbook, T, \& Greaves, J., the Emotional Intelligence Quickbook, Talent Smart 2003)

\section{'EI' Repercussions for Leaders}

Leaders must be applying 4 EQ skills for focus the organizational development, listen the people and make a practice:

1. Focused Observation and Situational Dynamics

2. Strategic Non-Reactive Thinking

3. Focused Observation and Situational Dynamics

4. Tactical Communications

\section{Increasing Self Awareness:}

Leader learns to "step outside!" watch and listen to Emotions and Responses carefully and consistently; Learn to Understand Proclivities. Track Tendencies in Emotionally Charged Situations and learn how emotions are affected by different people and situations. Understand what it is about the person or situation that elicits Reaction/Response. [Focused Observation and Situational Dynamics].

\section{Improve Self-Management:}

Analyze and problem solve before responding to significant challenges! Learn to catch emotions before they initiate! Plan \& prepare for difficult situations from what learned from Self-awareness. Discipline Yourself? Learn to Reshape \& Direct your Reactions! [Strategic Non-Reactive Thinking]

\section{Increasing Social Awareness:}

Always remember to Empathize! "Tune-In"- Focus and maximize powers of observation on the emotions, actions and reactions of others. Leaders should ask, listen and learn what Other People are Feeling. Look into and Understand their perspectives and sensibilities. Determine the factors that influence them positively $\&$ negatively [Focused Observation and Situational Dynamics]

\section{Improve Relationship Management:}

Understand that emotions play a role in every interaction between 2 or more People. By "Tuning Tuning-In" to emotions, leaders will understand the impact they leave on otherwise benign events.

- Leaders use emotions as a "Change Catalyst" to Positively Impact Interactions with others.

- Determine what they have a "Knack For" that helps maximize your relationships with others.

- Leaders use all these skills in forming solid relationships [Tactical Communications]

\section{Conclusion}

It is needless to say that the progress and prosperity of any organization depends upon the effective leadership skill and supportive personal with mental balance of its people. When the state of the mind people working for organization is balanced the success of organization is assured so management of emotions either self or others is an effective tool to control over all activity. Leaders should try to focus on individual, emotional and spiritual intelligence in progressive and control manner.O.IQ is organizational intelligence Quotient which is summation of all the quotients which exists in its human capital and to use them intelligently so as to respond smartly and sharply to ever changing environment. Four clusters like Self Awareness, Social Awareness, Self-management and Relationship management of competencies that shape emotional intelligence, also important for leaders and the inexplicable linkages between emotional intelligence and leadership. Emotional intelligence enhanced the leaders through various practices like Focused Observation and Situational Dynamics, Strategic Non-Reactive Thinking, Focused Observation and Situational Dynamics and Tactical Communications. 
In this article it is intended to bring out the different clusters of competencies that shape emotional intelligence, how it is important for leaders and the inexplicable linkages between emotional intelligence and leadership. It also underscores how emotional intelligence in leaders can be further enhanced so that they can turn into leaders' a unique.

\section{References}

The Practical Application of Emotional Intelligence(C) Arturo L. Jaramillo 2007.

Costa, P. T., \& McCrae, R. R. (1985). The NEO personality inventory manual. Odessa, Fl: Psychological Assessment Resources.

Trinidad, D. R., \& Johnson, C. A. (2011). The association between emotional intelligence and early adolescent tobacco and alcohol use. Personality and Individual Differences, 32, 95-105.

HRD NEWSLETTTER. Vol: 23 issue: 3, June 2007

Jonassen.c01, "What is Problem Solving?"

Research Technology Management; Volume 43. No. 1. January-February, 2000. pp 57-59. "Understanding the Difference Between Management and Leadership by Michael Maccoby" 